\title{
Biodistribution of Amine-Amide Chlorin e. Derivative Conjugate with a Boron Nanoparticle for Boron Neutron-Capture Therapy
}

DOI: $10.17691 / \mathrm{stm} 2016.8 .1 .05$

Received September 3, 2015

A.B. Volovetsky, PhD Student, Biophysics Department';

N.X. Shilyagina, PhD, Assistant, Biophysics Department';

V.V. Dudenkova, PhB Student, General Physics Department';

S.0. Pasynkova, Student, Department of Chemistry and Technology of Biologically Active Compounds named after N.A. Preobrazhensky;

M.A. Grin, DSC, Professor, Deputy Head of the Department of Chemistry and Technology of Bioactive Compounds named after N.A. Preobrazhensky²;

A.F. Mironov, DSc, Professor, Head of the Department of Chemistry and Technology of Bioactive Compounds named after N.A. Preobrazhensky2;

A.V. Feofanov, DSc, Head of the Laboratory of Optical Microscopy and Spectroscopy of Biomolecules;

I.V. Balalaeva, PhD, Associate Professor, Biophysics Department';

A.V. Maslennikova, MD, DSc, Professor, Oncology, Radiotherapy, Radiodiagnosis Department4; Professor,

Biophysics Department ${ }^{1}$

${ }^{1}$ Lobachevsky State University of Nizhni Novgorod, 23 Prospekt Gagarina, Nizhny Novgorod, 603950,

Russian Federation;

${ }^{2}$ Moscow Technological University, Institute of Fine Chemical Technologies, 86 Vernadskogo Avenue, Moscow,

119571, Russian Federation;

${ }^{3}$ Shemyakin and Ovchinnickov Institute of Bioorganic Chemistry, Russian Academy of Sciences,

16/10 Miklukho-Maklaya St., Moscow, 117997, Russian Federation;

${ }^{4}$ Nizhny Novgorod State Medical Academy, 10/1 Minin and Pozharsky Square, Nizhny Novgorod, 603005,

Russian Federation

The aim of the investigation was to study the biodistribution of amino-amide chlorin $\mathrm{e}_{6}$ derivative conjugate with cobalt bis-dicarbollide as a potential boron transporter for the tasks of boron neutron-capture therapy.

Materials and Methods. The experiments were carried out on Balb/c mice with induced murine colon carcinoma CT-26. Amino-amide chlorin $\mathrm{e}_{6}$ derivative conjugate with cobalt bis-dicarbollide was administered intravenously, the dose being 5 and $10 \mathrm{mg} / \mathrm{kg}$ body mass. The sampling for microscopic study of the drug uptake in ex vivo organs and tissues was performed $3 \mathrm{~h}$ after the administration.

Results. Characteristic nanoconjugate fluorescent peak was found in most organs under study, significant selectivity of the compound being noticed. A high uptake level was recorded in the liver, spleen and lung tissue. At the dose of $5 \mathrm{mg} / \mathrm{kg}$, the drug content in a tumor was not different from that in muscular tissue and skin; maximum uptake was found in the liver. If the dose was increased up to $10 \mathrm{mg} / \mathrm{kg}$, the nanoconjugate content in a tumor appeared to be comparable with that in the liver, the tumor/muscle ratio of fluorescent signals was $\sim 3$.

Conclusion. The study showed the prospects for using photosensitizer conjugate (chlorin $\mathrm{e}_{6}$ ) with boron particles as a means to deliver boron into a tumor. The level of the preparation uptake in tumor tissue depends on a dose.

Key words: boron neutron-capture therapy; chlorin $\mathrm{e}_{6}$; conjugate; photosensitizer; laser scanning microscopy.

Boron neutron capture therapy (BNCT) is a radiotherapy technique for malignancies characterized by high biological efficiency due to target radiation energy delivered directly to tumor cells. The method is based on relatively selective uptake of a non-radioactive isotope ${ }^{10} \mathrm{~B}$ in tumor cells and its further activation by a flux of thermal neutrons [1, 2]. Despite a high efficiency of the technique experimentally and clinically proved [3], up to the present, BNCT still cannot overstep the framework of clinical trials. There are several reasons for that, and one of them is the absence of effective techniques for boron delivery to tumor cells. The only approved compounds (3-(p-Boronophenyl)alanine: BPA, and sodium mercaptoundecahydro-closo-dodecaborate: $\mathrm{BSH}$ ) approved for clinical use do not exhibit high uptake selectivity in tumor tissue [4-7].

To solve the problem of targeted boron delivery to tumor cells, there have been suggested different synthesis strategies of boron-based compound conjugates with bioactive molecules able to accumulate in tumor cells (precursors of nucleic acids, amino acids and peptides, carbohydrates, acridines, different

For contacts: Artur B. Volovetsky, e-mail: voloveckiy91@gmail.com 
polyamines, as well as porphyrins and phthalocyanines) $[1,2,8,9]$. One of the most promising concepts in the sphere of preparations produced for BNCT is the use of porphyrin conjugates with polyhedral boron compounds. Oenbrink et al. were the first to study borated porphyrins for BNCT in 1988. Porphyrins and their boron derivatives were found to be able to accumulate in many solid tumors, they being two-in-one preparations: both boron delivery agents, and photosensitizers for photodynamic therapy [10]. The compounds of this category are bound through linker chlorin and boron polyhedron [11]. Representatives of such compounds effectively accumulate in tumor cells, while the use of carboranes as a boron element in a molecule enables an increase in the isotope concentration in a tumor and provides the boron moiety stability [12].

The essential stage preceding clinical trials is the study of pharmacokinetics of boron-based porphyrins, the assessment of their ability to accumulate and stay in a tumor at the higher concentration compared to healthy tissues, and then gets out of the body. Since the isotope ${ }^{10} \mathrm{~B}$ is non-radioactive, it can be neither used as a radioactive label, nor detected using appropriate techniques. In this case the key advantage of boronbased porphyrins is their ability to fluoresce that significantly facilitates the analysis of the preparation location and distribution in cells and living organisms using ex vivo and in vivo fluorescent imaging $[13,14]$. These techniques enable the study of the fluorophore biodistribution in the body and assess its uptake in a tumor and healthy tissues.

The aim of the investigation was to study the biodistribution of amino-amide chlorin $e_{6}$ derivative conjugate with cobalt bis-dicarbollide as a potential boron transfer in order to support boron neutron-capture therapy.

\section{Materials and Methods}

The compound under study, amino-amide chlorin $\mathrm{e}_{6}$ derivative conjugate with cobalt bis-dicarbollide (aminoalkyl-amide liker length, $\mathrm{n}=6$ ) (Figure 1 (a)) was synthesized according to the technique previously developed [15].

The absorption and fluorescent spectra of a conjugate were assessed by a spectrophotometerspectrofluorometer Synergy MX (BD, USA).

Animals and a tumor model. In vivo experiments were carried out in full agreement with the ethic principles established by European Convention for the Protection of Vertebrate Animals used for Experimental and other Scientific Purposes (adopted in 18.03.1986 in Strasburg and approved in 15.06.2006 in Strasburg) and approved by the Ethics Committee of Nizhny Novgorod State Medical Academy. The biodistribution of boron-based conjugate was analyzed in Balb/c mice (female, 18$20 \mathrm{~g}, \mathrm{n}=9$ ) supplied by the laboratory mouse facility of the Branch of Institute of Bioorganic Chemistry, Russian Academy of Sciences (Pushchino, Moscow region). The animals were kept in standard conditions of vivarium with a 12-hour light day.

For experimental tumors we used murine colon carcinoma CT-26 (No.CRL-2638 according to ATCC ${ }^{\circledR}$ catalogue). The cells were cultured in DMEM (PanEco, Russia) containing $2 \mathrm{mM}$ L-glutamine (PanEco, Russia) and $10 \%$ fetal calf serum (HyClone, USA), at $37^{\circ} \mathrm{C}$ and $5 \% \mathrm{CO}_{2}$, in culture bottles, $75 \mathrm{~cm}^{2}$ in area. At each passage stage the cells were treated with $0.25 \%$ solution of trypsin and versene (PanEco, Russia). Subculturing was performed 2-3 days later, when the culture confluence reached $80 \%$ [16].

To induce tumors the animals $(n=9)$ were injected with 1 million CT-26 cells in PBS, $100 \mu \mathrm{l}, 10 \mathrm{mM}$ (PanEco, Russia) subcutaneously in the thigh. The experiment was started on day $9-10$ after the injection, when the tumor node diameter reached $9 \mathrm{~mm}$.

In the study we used an initial solution of conjugate in cremophore, the active agent concentration being



Figure 1. Structural formula: black balls $\mathrm{C}-\mathrm{H}$, white balls $\mathrm{B}-\mathrm{H}$, a grey ball $\mathrm{D}-\mathrm{H}(\mathrm{a})$, as well as absorption $\varepsilon$ and fluorescence $\mathrm{I}_{\mathrm{fl}}$ spectra of amino-amide chlorin $\mathrm{e}_{6}$ derivative conjugate with cobalt bis-dicarbollide (b) 
$2 \mathrm{mg} / \mathrm{ml}$, which was diluted by physiological saline up to the concentration of $1 \mathrm{mg} / \mathrm{ml}$. The control group $(n=3)$ was not given the preparation. Three mice were injected with the conjugate using a dose of $5 \mathrm{mg} / \mathrm{kg}$ body mass, and three mice were given $10 \mathrm{mg} / \mathrm{kg}$. The solution was injected via the caudal vein, the injection volume being $100 \mu \mathrm{l} .3 \mathrm{~h}$ after the boron-based conjugate injection the animals were sacrificed by the cervical vertebrae dislocation. For further microscopic study we used the samples of the following organs and tissues: tumors, striated muscles, skin, liver, kidney, spleen, small intestine, lungs.

Sample preparation and microscopic study. An entire tumor was cut from the surrounding tissue and dissected along a longitudinal axis perpendicular to the thigh surface. The femoral muscle was cut along fibers, and the kidney was cut along the sagittal plane of the organ. The liver, lung and spleen were sectioned deep longitudinally. The samples were analyzed immediately after they were prepared, without being fixed or frozen. Throughout the investigation the humidity of the preparations was maintained by moistening them with physiological saline.

The images were taken using a confocal laser scanning microscope Axiovert 200M LSM510 META
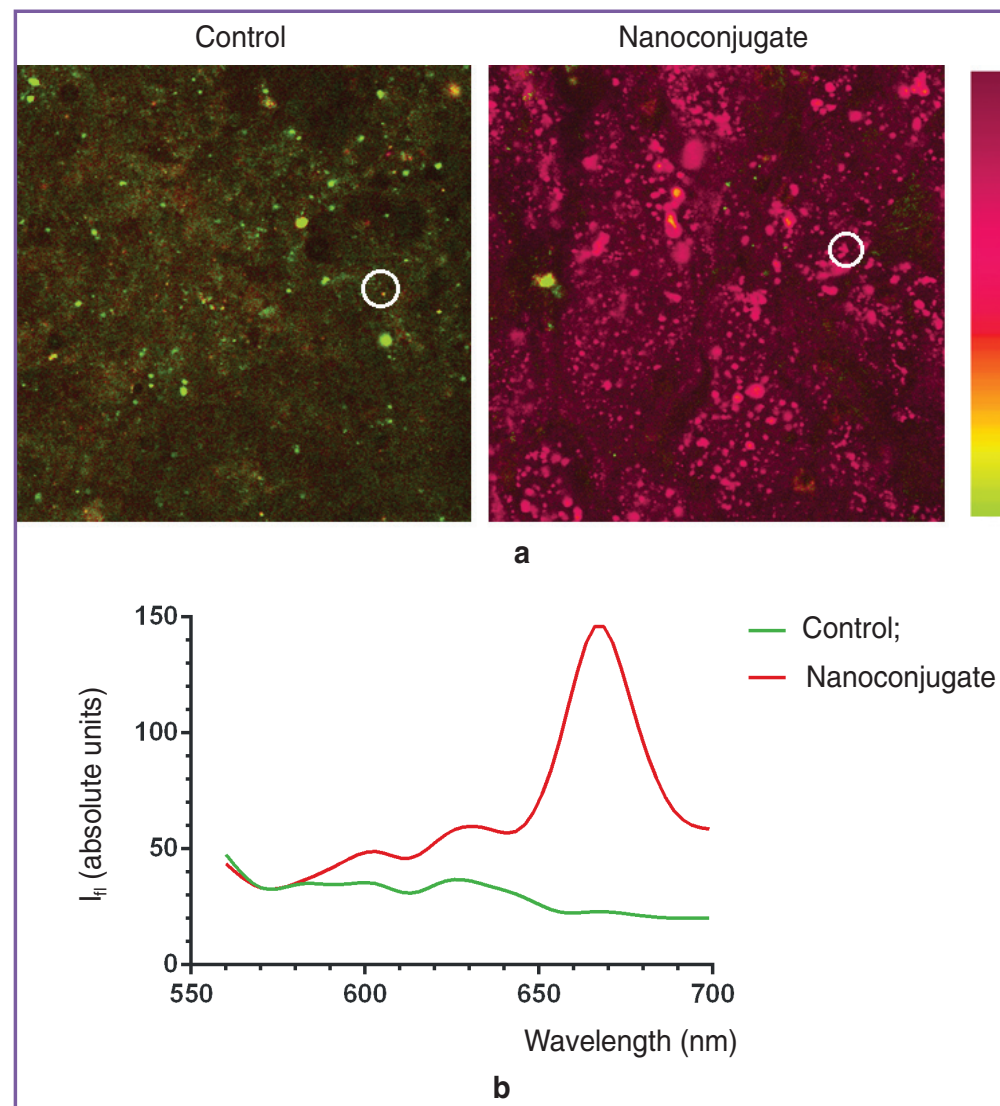

Figure 2. The images of tumor tissue samples of a control animal and an animal after a nanoconjugate injection (10 mg/kg, $3 \mathrm{~h}$ after injection) (a), as well as fluorescence $\mathrm{I}_{\mathrm{fl}}$ spectra of the circled areas (b). The size of the images is $225 \times 225 \mu \mathrm{m}$
(Carl Zeiss, Germany) with oil-immersion lens PlanApochromat, $\times 40$, with numerical aperture 1.3. Lateral resolution of the images was $1024 \times 1024$ pixels, pixel size being $0.22 \mu \mathrm{m}$. The conjugate fluorescence was excited at the wavelength of $514 \mathrm{~nm}$, a signal was recorded using a spectral module META in the 560$710 \mathrm{~nm}$ range at a pitch of $10 \mathrm{~nm}$. Spectral information enabled one to identify a nanoconjugate signal against the background of tissue autofluorescence. All the imaged were recorded under identical conditions.

Data statistical processing. Using the microscope software, from the obtained spectral image we selected a channel that corresponded to the fluorescent signal in the 650-693 $\mathrm{nm}$ range. Using the program ImageJ (version 1.47v) we determined an average signal level over the each imaged area of the studied samples of tumor and healthy tissues. For each healthy tissue sample we studied from 3 to 5 fields of view. When analyzing tumor tissue samples the fields of view were randomly selected from central and peripheral parts of a tumor node (at least 5 fields of view for each sample). The data were presented as a mean signal value in arbitrary units \pm a standard deviation for small samplings. For value comparison we used a one-way ANOVA test and Dunnett test.

Results and Discussion. The first stage of the investigation was to study optical properties of the obtained amino-amide chlorin $e_{6}$ derivative conjugate with cobalt bis-dicarbollide. The compound was characterized by intense light absorption in a visible spectrum with the peaks at 405, 500 and $665 \mathrm{~nm}$ that were close to chlorin $e_{6}$ peaks (Figure 1 (b)). Maximum fluorescence was found at $670 \mathrm{~nm}$. The previous experiments on cell cultures [14] revealed an intense accumulation of the conjugate in A549 line tumor cells, which was characterized with a cell/medium distribution factor of $\approx 80$. The property enables one to suggest the possibility to achieve a therapeutic dose necessary for BNCT, with higher contrast to healthy tissue and lower total toxicity in vivo. In vitro findings served as the basis to initiate the study on in vivo tumor models. The selection of experimental model CT-26 was due to high vascularization of a growing tumor [17].

The study of tumor tissue samples revealed an intense fluorescent signal in it (Figure 2 (a)) at both nanoconjugate doses $3 \mathrm{~h}$ after the injection. Maximum fluorescence was 


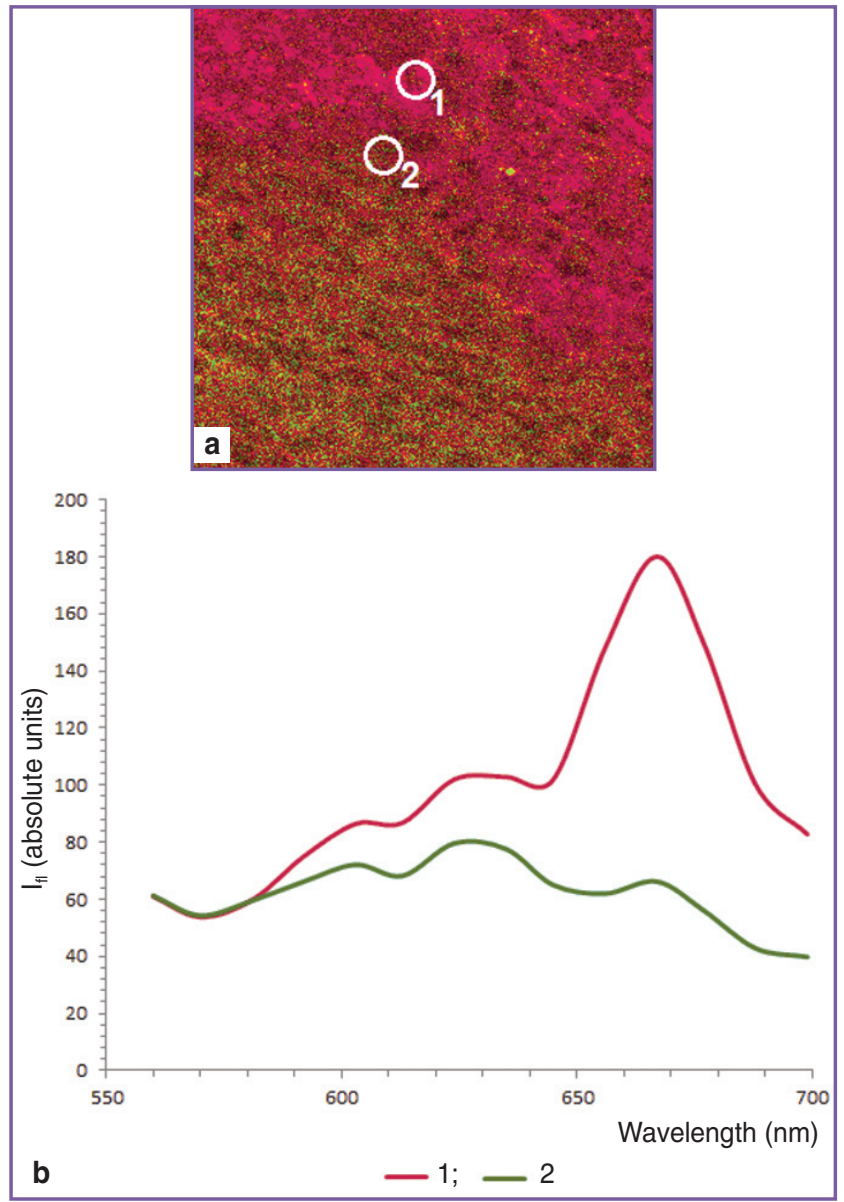

Figure 3. The images of the areas with different nanoconjugate uptake $(1,2)$ in animal tumor tissue after being injected (10 mg/kg, $3 \mathrm{~h}$ after injection) demonstrate the non-uniformity of its distribution (a), as well as fluorescence $I_{f l}$ spectra of these areas (b). The size of the images is $125 \times 125 \mu \mathrm{m}$. Figure 2 shows the color code found at 665-670 nm (Figure 2 (b)), which corresponded to spectrum of the conjugate under study.

The specific characteristic of fluorophore uptake in a tumor was its non-uniformity in different tumor parts (Figure 3). One might assume that the phenomenon is due to the so called EPR-effect (enhanced permeability and retention effect), i.e. the peculiarities of the tumor vasculature including the non-uniformity and chaotic state of forming vessels [18].

Characteristic fluorescence peak of the conjugate was found in most organs under study; in addition, the compound was characterized by significant uptake selectivity (Figure 4).

High conjugate uptake level was recorded in the liver, kidneys, spleen and lung tissue that is consistent with the pharmacokinetics data received for preparations of chlorin family, and associated with morphofunctional characteristics of these organs [19]. A conjugate signal in skeletal muscles, as well as in muscular walls of hollow organs (stomach, intestines, heart), was significantly lower. Moreover, skin samples demonstrated nearly total absence of conjugate uptake. $3 \mathrm{~h}$ after the injection, a considerable amount of the substance remained in the circulation and was recorded in major vessels of different organs (Figure 4 shows the vessels feeding the skeletal muscle).

A quantitative analysis of the fluorescent signal level in tissue samples enabled one to reveal the dependence of nanoconjugate uptake on a preparation dose. After the conjugate injection, $5 \mathrm{mg} / \mathrm{kg}$, its content in a tumor differed slightly from that in muscular tissue and skin, its maximum uptake being found in the liver (Figure 5).

If a dose is increased up to $10 \mathrm{mg} / \mathrm{kg}$, the nanoconjugate content in a tumor appeared to be compatible with that in the liver, and the tumor/muscle
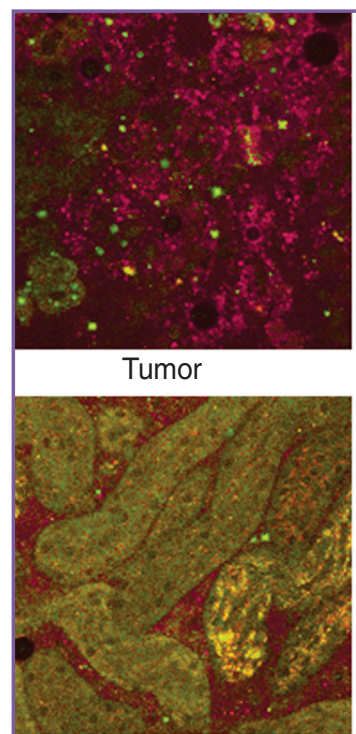

Kidneys



Muscles



Spleen

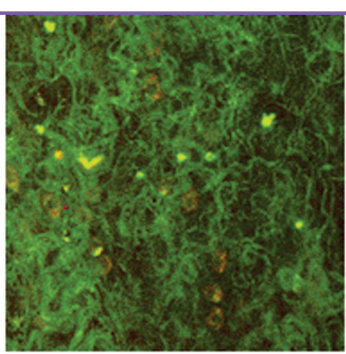

Skin

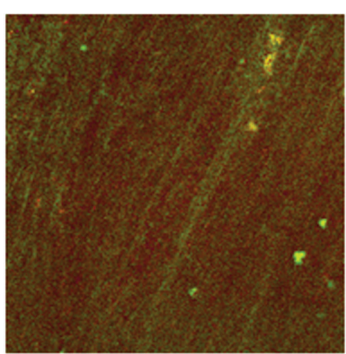

Intestinal wall



Liver

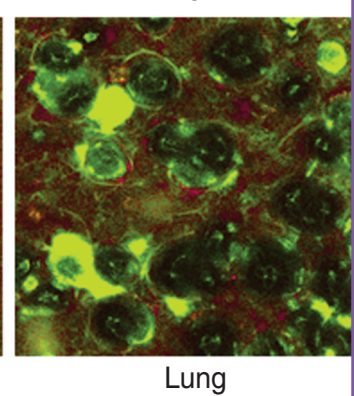

Figure 4. The images of animal tissue samples $3 \mathrm{~h}$ after nanoconjugate $(10 \mathrm{mg} / \mathrm{kg})$ injection. The size of the images is $225 \times 225 \mu \mathrm{m}$. Figure 2 shows the color code 


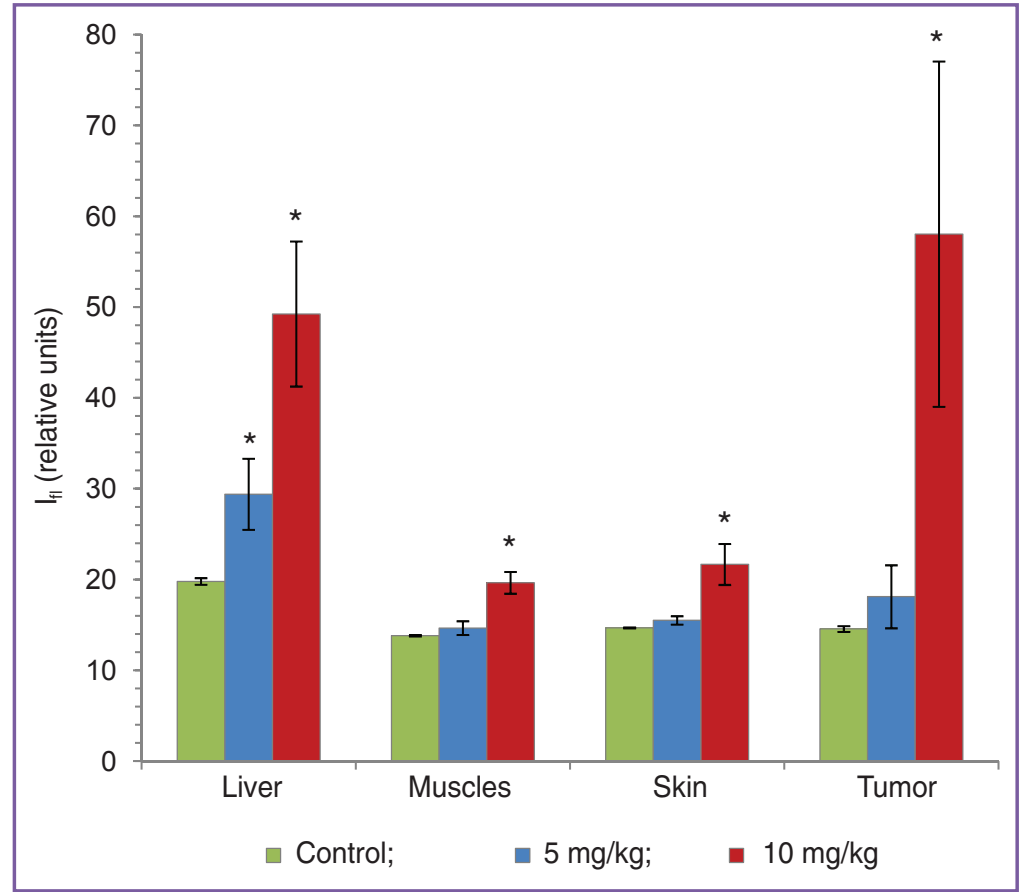

Figure 5. The fluorescent signal level $\mathrm{I}_{\mathrm{fl}}$ of tissue samples in control animals and the animals injected different nanoconjugate doses. * statistically significant variation from the control

ratio for fluorescent signals was $\sim 3$. It should be mentioned that the standard deviation of a signal level in a tumor was high if the nanoconjugate was injected at the dose of $10 \mathrm{mg} / \mathrm{kg}$ that was consistent with the microscopic study findings, when the tumor was found to have both the areas with high and average signal levels (See Figure 3).

Thus, the preliminary study showed a boronbased conjugate of chlorin to meet the requirements for preparations used for BNCT [2]. In particular, the compound demonstrated its ability to relatively selective uptake in a tumor, the "tumor/healthy tissue" ratio being $3: 1$. The conjugate exhibited low uptake in skin that enables one to expect its low phototoxicity and safety when used in the light. Chlorin property to fluoresce enables to control the boron content in tissues using in vivo techniques. These facts enable one to conclude the application perspectiveness of boron-based conjugates as the agents to deliver boron in BNCT. The next stage of the work will be the study of conjugate pharmacokinetics, as well as the analysis of boron content in a tumor and healthy tissues in order to develop optimal conditions and further radiation exposure.

Conclusion. The study of biodistribution of a photosensitizer conjugate (chlorin $\mathrm{e}_{6}$ ) with cobalt bisdicarbollide demonstrated the perspectiveness of its application as a boron delivery means to a tumor. The uptake level of a conjugate in a tumor tissue depends on the dose administered.

Study Funding. This study was supported by a grant
Russian Foundation for Basic Research No.14-02-00715.

Conflicts Interest. The authors have no conflicts of interest to disclose.

\section{References}

1. Sivaev I.B., Bregadze V.I., Kuznetsov N.T. Derivatives of the closo-dodecaborate anion and their application in medicine. Russian Chemical Bulletin 2002; 51(8): 1362-1374, http://dx.doi. org/10.1023/A:1020942418765.

2. Rozumenko V.D. Boron neutroncapture therapy of brain tumors. Ukrainskiy neyrokhirurgicheskiy zhurnal 2001; 3: 4-12.

3. Hartman T., Carlson J. Radiation dose heterogeneity in receptor and antigen mediated boron neutron-capture therapy. Radiother Oncol 1994;31(1):61-75, http://dx.doi.org/10.1016/01678140(94)90414-6.

4. Boron chemistry at the beginning of the 21st century. Bubnov Yu.N. (editor). Moscow: Editorial URSS; 2003; 376 p.

5. Soloway A.H., Tjarks W., Barnum B.A., Rong F.G., Barth R.F., Codogni I.M., Wilson J.G. The chemistry of neutron-capture therapy. Chem Rev 1998; 98(4): 1515-1562, http://dx.doi. org/10.1021/cr941195u.

6. Yokoyama K., Miyatake S., Kajimoto Y., Kawabata S., Doi A., Yoshida T., Asano T., Kirihata M., Ono K., Kuroiwa T. Pharmacokinetic study of BSH and BPA in simultaneous use for BNCT. J Neurooncol 2006; 78(3): 227232, http://dx.doi.org/10.1007/s11060-005-9099-4.

7. Goudgaon N.M., El-Kattan G.F., Schinazi R.F. Boron containing pyrimidines, nucleosides, and oligonucleotides for neutron capture therapy. Nucleosides and Nucleotides 1994; 13(1-3): 849-880, http://dx.doi.org/10.1080/15257779408013283.

8. Neutron capture therapy - principles and application. Sauerwein W., Wittig A., Moss R., Nakagawa Y. (editors). Springer Science + Business Media; 2012, http://dx.doi. org/10.1007/978-3-642-31334-9.

9. Yamamoto Y., Cai J., Nakamura H., Sadayori N., Asao N., Nemoto H. Synthesis of netropsin and distamycin analogues bearing o-carborane and their DNA recognition. Journal of Organic Chemistry 1995; 60(11): 3352-3357, http:// dx.doi.org/10.1021/jo00116a018.

10. Oenbrink G., Jurgenlimke P., Gabel D. Accumulation of porphyrins in cells influence of hydrophobicity aggregation and protein binding. Photochem Photobiol 1988; 48(4): 451-456, http://dx.doi.org/10.1111/j.1751-1097.1988.tb02844.x.

11. Grin M.A., Titeev R.A., Brittal D.I., Chestnova A.V., Mironov A.F., Feofanov A.V., Lobanova I.A., Sivaev I.B., Bregadze V.I. Synthesis of cobalt bis(dicarbollide) conjugates with natural chlorins by the Sonogashira reaction. Russian Chemical Bulletin 2010; 59(1): 219-224, http://dx.doi. org/10.1007/s11172-010-0065-8.

12. Efremenko A.V., Ignatova A.A., Grin M.A., Mironov A.F., Bregadze V.I., Sivaev I.B., Feofanov A.V. Confocal microscopy and spectral imaging technique: contribution to the development of neutron sensitizers for anticancer BNCT. In: Current microscopy contributions to advances in science and technology. Méndez-Vilas A. (editor). Spain: FORMATEX, 2012; p. 84-90. 
13. Ol'shevskaya V.A., Zaytsev A.V., Savchenko A.N., Shtil A.A., Cheong C.S., Kalinin V.N. Boronated porphyrins and chlorins as potential anticancer drugs. Bulletin of the Korean Chemical Society 2007; 28(11): 1910-1914.

14. Efremenko A.V., Ignatova A.A., Grin M.A., Sivaev I.B., Mironov A.F., Bregadze V.I., Feofanov A.V. Chlorin $e_{6}$ fused with a cobalt-bis(dicarbollide) nanoparticle provides efficient boron delivery and photoinduced cytotoxicity in cancer cells. Photochem Photobiol Sci 2014; 13(1): 92-102, http://dx.doi. org/10.1039/c3pp50226k.

15. Grin M.A., Titeev R.A., Brittal D.I., Ulybina O.V., Tsiprovskiy A.G., Berzina M. Ya., Lobanova I.A., Sivaev I.B., Bregadze V.I., Mironov A.F. New conjugates of cobalt bis(dicarbollide) with chlorophyll a derivatives. Mendeleev Communications 2011; 21(2): 84-86, http://dx.doi.org/10.1016/ j.mencom.2011.03.008.

16. Freshni R.Ya. Kul'tura zhivotnykh kletok: prakticheskoe rukovodstvo [Culture of animal cells: practice guidelines]. Moscow: BINOM. Laboratoriya znaniy; 2010; 691 p.

17. Kuznetsov S.S., Snopova L.B., Karabut M.M., Sirotkina M.A., Buyanova N.L., Kalganova T.I., Elagin V.V., Senina-Volzhskaya I.V., Barbashova L.N., Shumilova A.V., Zagaynova E.V., Vitkin A., Gladkova N.D. Features of morphological changes in experimental CT-26 tumors growth. Sovremennye tehnologii $v$ medicine $2015 ; 7(3)$ : 32-39, http:// dx.doi.org/10.17691/stm2015.7.3.04.

18. Maeda $\mathrm{H}$. Macromolecular therapeutics in cancer treatment: the EPR effect and beyond. Journal of Controlled Release 2012; 164(2): 138-144, http://dx.doi.org/10.1016/ j.jconrel.2012.04.038.

19. Juzeniene A. Chlorin $e_{6}$-based photosensitizers for photodynamic therapy and photodiagnosis. Photodiagnosis Photodyn Ther 2009; 6(2): 94-96, http://dx.doi.org/10.1016/ j.pdpdt.2009.06.001. 